\author{
Dawid Zawadzki, Paulina Pędziwiatr, Karina Michalska \\ Research and Innovation Centre Pro-Akademia \\ 9/11 Innowacyjna Street, 95-050 Konstantynów Łódzki, Poland, dawid.zawadzki2010@gmail.com
}

\title{
A NOVEL MICROBIAL FUEL CELL WITH EXCHANGABLE MEMBRANE - APPLICATION OF ADDITIVE MANUFACTURING TECHNOLOGY FOR DEVICE FABRICATION
}

\begin{abstract}
Research about exploitation the potential of waste and sludge increased drastically in the recent years. One of the most promising alternative methods of waste management is Microbial Fuel Cell (MFC), which generate clean bio-electricity using microorganisms. Organic compounds, sewage, municipal solid waste could be used as a source for microbial nutrition. The construction of MFC is one of the most important parameter in laboratory studies and during scale-up. The efficiency of MFC depends on many factors including type of membrane. To obtain optimization in terms of various operating conditions, a prototype of Microbial Fuel Cell with exchangeable membrane was projected and fabricated by additive manufacturing (AM) technology. This novel device allows to research effects of different types of separator membranes. Preliminary research showed possibility to produce 3D printed MFC systems.
\end{abstract}

\section{Key words}

Microbial fuel cell, microorganisms, exchangeable membrane, bioelectricity, additive manufacturing

\section{Introduction}

According to the increasing electrical energy demand, resource limitation and environmental pollution, there is actually common consensus to use renewable energy sources instead of fossil fuels. This has resulted in the emergence of eco-friendly, alternative power source, which are neutral to greenhouse effect. In recent years, an increasing interest in a solution enabling to gain energy and raw material from waste by bioconversion is being observed. Biotransformation is a conversion of organic materials, such as biodegradable waste, into usable products or energy sources. The transformation is possible because of biological processes or agents, such as certain microorganisms, bacteria, some detritivores or enzymes.

Fuel cells are electrochemical devices that produce energy in the form of electricity as a result of a chemical reaction (energy is stored in molecular bonds). Since 1911, when the bacteria that could produce electricity were discovered, interest in this ability and associated technologies, which exploit the electric potential of microbes, has grown [1,2]. One of the most promising solutions, which makes use of biotransformation, is Microbial Fuel Cell (MFC) [2]. A microbial fuel cell is a man-made biological system in which electric energy is directly produced from biodegradable matter in presence of microorganisms.

In MFCs bacteria or microorganisms are being used as the catalysts to oxidize organic and inorganic matter and generate electrical current [3]. The fuel cell provides the natural environment for biological processes and leads to the necessity for ensuring adequate living conditions for microorganisms. During consumption of feedstock microorganisms produce electrons, which, after being released are thereafter transported to the electron acceptor. Hence, microbacterial energy is directly converted to electricity. Simplified working principle is shown in Fig. 1. Microorganisms grow in the surface of conductive anode in anaerobic chamber. Generated electrons are transported into cathode placed in aerobic chamber. Two chambers are physically separated by membrane, which enables protons movement. 


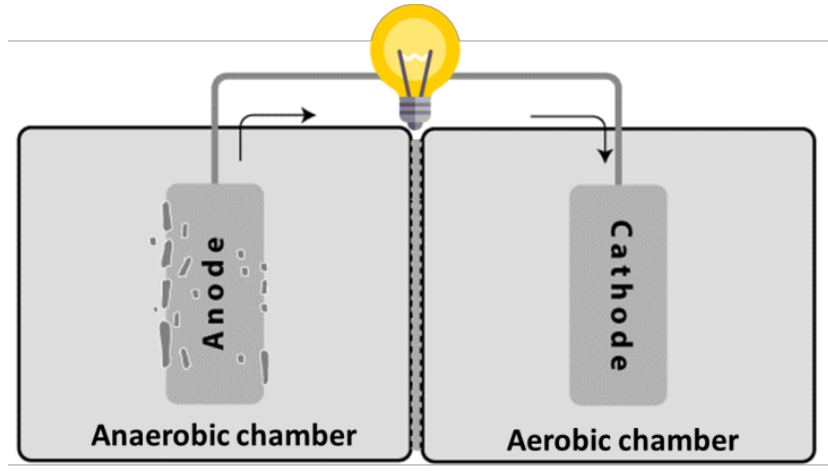

Fig. 1. Operating principle of MFC Source: Author's

Most MFCs contain a membrane to separate the chambers. In anode compartment, oxidation takes place while in the cathode, reduction process is observed. During oxidation the electrons are produced and transferred directly to an electrode or, to a redox agent. The electron flux is transported to the cathode. By convention, a positive current flows from the positive to the negative terminal, in a direction opposite to that of electron flow [4]. Next steps of the process are presented in Fig. 2.

\begin{tabular}{|c|c|c|c|}
\hline $\begin{array}{l}\text { The microbial } \\
\text { (normally a } \\
\text { bacteria) } \\
\text { consumes } \\
\text { (oxidizes) fuel } \\
\text { that passes into } \\
\text { the anode }\end{array}$ & $\begin{array}{l}\text { Liberating } \\
\text { electrons which } \\
\text { it transfers into } \\
\text { an electrode } \\
\text { wire linking the } \\
\text { anode with the } \\
\text { cathode }\end{array}$ & $\begin{array}{l}\text { Hydrogen } \\
\text { proton } \\
\text { charges pass } \\
\text { from the } \\
\text { anode to the } \\
\text { cathode via } \\
\text { the proton } \\
\text { exchange } \\
\text { membrane }\end{array}$ & $\begin{array}{l}\text { The hydrogen } \\
\text { combines with } \\
\text { the oxygen in } \\
\text { electron charges } \\
\text { for form water } \\
\text { and completes } \\
\text { the circuit, } \\
\text { producing } \\
\text { power }\end{array}$ \\
\hline
\end{tabular}

Fig. 2. Process of bioelectricity generation in MFC Source: Author's

Electrical output is limited in MFCs and one aspect of this limitation might be directly related to the microorganisms that are established on the anode and their extracellular electron transfer efficiency [5].

Many researches about exploitation of MFC in power extraction from wastewater in the form of electricity by the bioconversion process were conducted all over the world. The results indicated that it is possible to realize the electricity generation by MFC. Sludge store nine times more energy than it is needed to their disposal using conventional method [6]. The idea of using microorganism as biocatalyst in fuel cells is not novel, it has more than 100 years old history. Researches on this field were conducted most intensively in the 60s and 70s of the last century $[7,8]$. It is extensively thought that efficient production of electric energy using MFC necessitate the addition of expensive exogenous mediators. However, in 1999 a cell which energy was generated by natural existing bacteria, without using additional mediators [9]. The results of this discovery led to renewing the interest in this topic, especially in the face of the need of inventing new, alternative renewable power sources. Therefore, MFC became a promising technology, allowing to gain electric energy [10].

There are different types of microbial electrochemical technologies (MET) - microbial fuel cells (MFC) and microbial electrolysis cells (MEC). MEC is partially reversing the process to generate hydrogen or methane from organic material by applying an electric current.

\section{Efficiency MFC and key parameters - theory}

MFC construction

The principle of operating the easiest MFC depends on converted chemical energy, contained in compound, directly to electric energy. It is possible thanks to microorganism oxidizing organic matter in anodic compartment and transferring electron on closely located electrode while protons are being released to solution. This process occurs in anaerobic condition. Electrons are moving to cathode, through external electric circuit. It causes potential difference between anode and cathode and generation of electric current. 
Simultaneously protons, generated on anode migrate through semipermeable membrane to oxygenated cathode. On cathode there is chemical or microbiological process of reduction, where protons combine with electrons and oxygen created water [11].

There are many different components of MFCs which are key factors in MFC constructions and operation. Electrodes, wirings, material of cell and size play an important role. Apart from that fuel cells can be classified in two types on the basis of number of compartments or chambers. Anodic chamber contain organic substances that are consumed by microbes, which simultaneously generating electron and proton. Cathode chamber is filled with electron acceptor, which not interferes with microorganisms. According to the upon requirements, the most simple MFC prototype is double or single chambered.

Dual chamber cell was first and the easiest model of MFC. Microbiological cells could function also in other configuration. In view of necessity continuous aeration solution in cathode compartments in order to furnish oxygen for reduction reaction, modification this basic model was started. The main aims of changes were implemented to reduce processes costs and to increase the efficiency of MFC. The one chamber cells have been constructed, in which resigned from membrane separate both electrode and cathode have directly contact with air $[12,13]$. In a single compartment MFC System, an anodic chamber is connected to a porous air cathode. Transfer of electron to cathode, separated by gas diffusion layer to complete circuit. This type of MFC is more versatile because of limited requirement of periodic recharging with oxidative agent. Moreover, onechamber construction ensures flexibility and lower investment costs. Also proposed another cell's configuration: flat [14], cylindrical, tubular [15] or grouped in systems enabling efficient continuous operation of these bioreactors [16]. Introduced difference concerned also way feed cells, for example substratum was doze to anode chamber continuously or in parties [17]. In open sedimentary systems used electrode combination to obtain energy, used to power telemetry device on bottom of sea or ocean [18]. Generally, in double compartment MFC systems consist of an anodic and cathodic chamber separated by proton exchange membrane, which allow proton transfer, while disallow diffusion of oxygen into anode. This type of construction is commonly used to waste treatment in lab-scale evaluation.
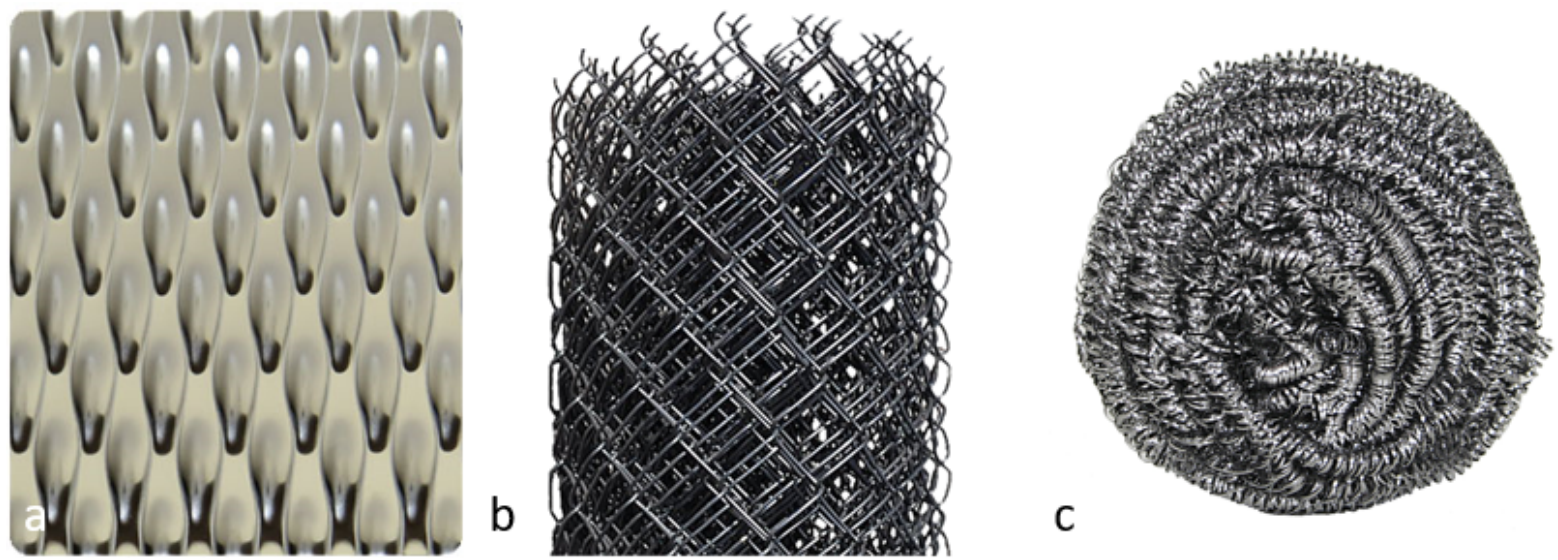

Fig.3. Different type of electrode: a) flat electrode, b) net electrode, c) steel wool electrode Source: Author's

MFCs are being constructed using a variety of materials, and in an ever increasing diversity of configurations (see Fig. 3). The types of materials applied successfully as MFC's electrodes as well as their architecture details were previously described [19]. During laboratory studies MFC systems are tested under a range of conditions that include differences in temperature, electrode surface areas, $\mathrm{pH}$, type of membrane, electron acceptor, size and operation time.

\section{Microorganisms which produce electricity}

Energy production in microbiological fuel cells is possible due to microorganisms, mainly bacteria, which after oxidizing substratum to carbon dioxide while protons and electrons are releasing, transport the latter outside cell. Part of species additionally instead transport electrons on exogenous acceptor, forward it directly an anode. Such a phenomenon is named exoelectrogenesis [20]. 
Main source of microorganism to MFC is usually rich in microorganism sediments, soil or waste samples. [21, 22]. In addition, attempts are often made to use previously activated sludge derived from plant-based wastewater treatment processes or from other previously operated MFCs [23, 24, 25]. Usually mixed culture of microbes is used for anaerobic digestion of substrate as complex mixed culture permits broad substrate utilization.) . Organic component like: marine sediment, soil, wastewater and activated sludge are rich source of microbes that can be used in MFCs catalytic units. Because of using various type of inoculum in the anode chamber representatives of many species of microorganisms can be found in the biofilm. In addition to the numerous unidentified organisms, are among them bacteria belonging to classes: Alfaproteobacteria, Betaproteobacteria, Gammaproteobacteria, Deltaproteobacteria, Clostridia, Bacteroidetes, Flavobacteria, Sphingobacteria, Deferribacteres, Spirochaetes, Planctomycetes, Nitrospirales [26, 27, 28]. Undoubtedly, the bacteria themselves are used properly in all current MFCs [29].

Diversity of microbial communities within MFC is determined not only by origin of sample inoculum, but also kind of fuel, presence of mediators or oxygen conditions in bioreactor [27]. To avoid compete oxygen with electron carries (mediators), in mostly MFC anode should be placed under anaerobic conditions [26]. In energy generating systems, in precisely anaerobic conditions, Geobacter, pose over $70 \%$ of all microorganisms present on anode surface and initially suspected, that this type of bacteria plays a major role in energy generation. But in another MFC, where reactor allows to oxygen leak to anode chamber, dominate organism more tolerant of oxygen [17]. In most case in community of microorganism dominant are representatives of Gram-negative species of bacteria belonging to type Proteobacteria, but species composition and quantity representatives belonging to particular classes is changing depending on inoculum type, using in cell or material from which anode was made $[21,30]$.

The most effective MFCs utilize multi- species bioanode where microbes have grown as a biofilm [31]. Mixed culture or microbial consortia seem to be more durable and efficient than single strains, which require sterile conditions. What is more isolation of mixture of species from natural sources is much easier and the total cost of the process is lower. There are some regular MFCs designs which explore metabolic tendency of single microbial species to generate electricity, for example: Shewanella species, Pseudomonas species, Geobacter species [32]. The use of pure cultures has also some technical limitations [23].

\section{$\underline{\text { Substrates }}$}

MFCs offer the possibility of extracting electric current from a wide range of soluble or dissolved complex organic wastes and renewable biomass. A large number of substrates have been explored as feed, the pure substances as: glucose, cysteine, ethanol, acetate or mixture of biodegradable organic waste: municipal solid waste, industrial and agriculture wastewaters. The major substrates that have been tried include various kinds of artificial and real wastewaters and lignocellulosic biomass [2]. Substrate is a key factor for efficient production of electricity from MFCs. Dry wastewater and landfill leachates could be also used as an unconventional substrate form bioelectricity generation in MFC.

\section{Membranes}

Membrane is one of most important part of a MFC. It allows proton exchange but also separate the aerobic and anaerobic chamber. The main purposes of the membrane: reduce the substrate flow from the anode to cathode chamber, avoid the back-diffusion of the electron acceptor, and increase the efficiency. The membrane should also not allow either gas to pass to the other chamber - this problem is named gas crossover [33]. Splitting of the hydrogen molecule is easier by using a platinum catalyst. However, it is to split the oxygen molecule, and this causes electric losses. Today the platinum is the best option because more appropriate catalyst material for this process has not been discovered.

Many different types of membranes are used in microbial fuel cells. The most commonly used membrane is Nafion - one of proton exchange membrane (PEM), because of its excellent thermal and mechanical stability. Power generation in microbial fuel cells (MFCs) is a function of the surface areas of the proton exchange membrane (PEM) and the cathode relative to that of the anode. Pores in Nafion structure allow movement of cations but the anions or electrons are not conducted. Nafion could be manufactured with much different cationic conductivity [34]. The nanoporous membrane that uses a non-PEM to generate passive diffusion within the cell was recently developed. The membrane is a nonporous polymer filter (polycarbonate cellulose, nylon) which offers comparable power densities to Nafion (a traditional PEM) with greater durability. Porous 
membranes simplify passive diffusion by that means reducing the power supplied to the MFC in order to keep the PEM active and increasing the energy output.

Membraneless MFCs can deploy anaerobic bacteria in aerobic environments. However, membraneless microbial fuel cells make that cathode contamination contain the indigenous bacteria and the power-supplying microbe. The novel passive diffusion of nonporous membranes allows achieving the advantages of a membrane-less MFC without problems with cathode contamination. What is more, nanoporous membranes are cheaper than Nafion (Nafion-117, $\$ 0.22 / \mathrm{cm} 2$ vs. polycarbonate, $<\$ 0.02 / \mathrm{cm} 2$ ) [35].

PEM membranes could be also replaced with ceramic materials, which costs can be as low as $\$ 5.66 / \mathrm{m} 2$. Good transport of ionic species is possible because of the macroporous structure of ceramic membranes allows. The materials used in ceramic MFCs are earthenware, alumina, terracotta, mullite and pyrophyllite [36].

According to the presence of membrane, there have occurred problems such as biofouling, limited proton transfer and high costs of the traditional PEM membranes. To avoid that situation, research by removing the membrane from the MFC is still conducted. There are some experimental data which show that membraneless MFC has high proton transfer rate and lower cell internal resistance. Unfortunately, it is connected with oxygen diffusion in the vicinity of anode, what makes that CE of the MFCs is dropped off by about 20\% [32]. What is more, membraneless MFC leads to assemble biofilms on cathode surfaces which cause that the diffusion of oxygen is limited and by that, reduces MFC efficiency.

There are many advantages of membraneless technology like no membrane internal resistance membrane, no biofouling issues, and lower MFC operational costs. Membraneless technology is not advisable for long term MFC performance because of high oxygen and substrate crossover rate which can result in lower MFC efficiency.

\section{Applications}

MFCs have been studied as a renewable energy source. Unfortunately, application of MFCs is actually limited. With further improvements in cost effectiveness, design, and efficiency based on these near-term applications, there is a possibility to scale-up and use MFCs as a renewable energy resource.

Microorganisms could perform the double duty of generating power and degrading effluents in wastewater treatment. Actually MFCs are under serious consideration as equipment to produce electrical power in the course of treatment of agricultural, industrial and municipal wastewater. When microbes oxidize organic compounds in wastewater, electrons are released yielding a steady source of electrical current. If power generation in these systems could be increased, MFCs can provide a new method to makes operating costs of waste water treatment plants lower. Advanced waste water treatment could be more affordable in both industrialized and developing nations. What is more, MFCs are also known to generate less excess sludge if they compared to the aerobic treatment process [21, 22].

To understand and model ecosystem responses, data on the natural environment are required. Sensors distributed in the natural environment could not work without power for operation. It is a possibility to use MFCs to power such devices, in water environments where it is difficult to routinely access the system to replace source of electric. Power densities are lower in sediment fuel cells because of the lower organic matter concentrations and their higher intrinsic internal resistance. The low power density could be offset by energy storage systems which release data in bursts to central sensors [37].

The power requirement for electronic devices has been reduced due to development of micro-electronics and related disciplines. Traditionally, batteries are used to power chemical sensors and telemetry devices, but in some applications replacing batteries on a regular basis is impractical, time-consuming, and costly. MFCs could be a possible solution to this problem. Using self-renewable power supplies, which can operate for a long time using local resources could be promising application of MFCs. Researchers should focused on selecting suitable organic and inorganic substances that could be used as sources of energy [38].

Another potential application of the MFCs is to use it as a sensor for pollutant analysis and in situ process monitoring and control. Biological Oxygen Demand (BOD) is the amount of dissolved oxygen required to meet the metabolic needs of aerobic microorganisms in water rich in organic matter, for example: sewage. The 
correlation between the concentration of assimilable organic contaminants in wastewater and the coulombic yield of MFCs makes MFCs possible to use it as BOD sensors. An MFC-type BOD sensor could be kept operational for over five years without extra maintenance, longer in service life span than different types of BOD sensors [39].

MFCs operating on organic waste could be an interesting alternative for hydrogen production. In such devices, anaerobic conditions are maintained in the cathode chamber and additional voltage is applied to the cathode. According to this, protons are reduced to hydrogen on the cathode [40].

\section{Project of microbial fuel cell with exchangeable membrane - experimental studies}

Up to now much attention has been paid to the improvement of both MFC architecture and component materials to obtain better overall performance. However, there is still lack of knowledge about selection of potentially attractive materials with high surface area for MFC fabrication, as well as novel techniques for rapid and stable prototyping and manufacturing. Many studies published to date concern bioelectrochemical systems (BES) made out of mainly Plexiglas or glass. On the other hand, only a small part of available data was obtained in systems built from other casings like nanocure, polypropylene or polycarbonate, which seem to be very promising due to their structural properties. Thus, there is still a research gap for experimental work with thermoplastics that could lead to developing novel and much more beneficial solutions in the field of BES constructing. As it was mentioned above the performance of MFC depends not only on both electrodes materials and characteristics (e.g. surface area, conductivity, chemical stability and biocompatibility), but also on the geometry of the system, and on the internal surface of the bioreactor. Thus, in the last decades engineers made the effort to improve and simplify the fabrication procedures. The usage of popular glass or Plexiglas materials for building the MFC devices limits significantly the range of possible shapes and incorporating more detailed, small-scale elements into the outer packaging. Moreover, the process of manufacture is much more laborious, time-consuming, expensive and requires very precise work. Therefore, a completely new approach based on the Additive Manufacturing (AM), also named 3D-printing, has been proposed and tested within this work. It has already been examined for medical applications (implants, tissue engineering), building industry, wind turbines designing and fabrication etc., where it ensured lots of improvements, also from economic point of view. AM techniques can be applied for fabrication of a MFC that can promote biofilm formation. Such casing does not contain any other additional elements like clamps, screws or clips. It also does not require gaskets or sealants preventing from leakage that are common in BES made out of e.g. Plexiglas. The need for assembly can be reduced or even eliminated and the unit can be rich in microdetails and thus very complex and intricate. High degree of design freedom, utilizing flexible, thermo-plastic materials (filaments) allow to precise manufacturing of bioreactor surface with a high surface area and with a variety of shapes and sizes.

\section{Objectives}

The usefulness of 3D-printing technology and wide range of its capabilities for monolithic MFC fabrication will be demonstrated. Only a few papers $[41,42,43,44]$ propose utilization of 3D-printed bioreactors or their components instead of the classic, Plexiglas or glass devices. AM offers the ability to produce complex geometries at relatively high speeds. Taking into account the multitude of benefits offered by AM in terms of fast and precise designing and production process, such technique should be considered as a most perspective in the near future. The process of system designing and optimisation can be facilitated and improved by the use of 3D-printing, through elimination of the need for costly assembly and multi-part, time-consuming production. Moreover, it offers also a significant degree of design freedom and eliminates human errors. By changing the design parameters of each component such as surface area, shape, printing resolution, thickness and extent of filling, the structure of printed device can be easily manipulated and, in consequence its performance can be quickly improved. This is a great and general advantage of applying 3D-printing technology for MFC fabrication.

The aim of this work was to:

- Design Double compartment MFC consist of anode and cathode parts, physically separated by a membrane with movable module for exchangeable membrane.

- Apply the AM technology for MFC fabrication.

- Conduct an experiment and confirm the potential of 3D-printed MFC for the lab-scale experiments. 


\section{Design of MFC and printing procedure}

Simple model of double compartment MFC was designed using Solidworks software. Size of the designed bioreactor: $120 \mathrm{~mm} \times 92 \mathrm{~mm}$, size of membrane: $90 \mathrm{~mm} \times 80 \mathrm{~mm}$.

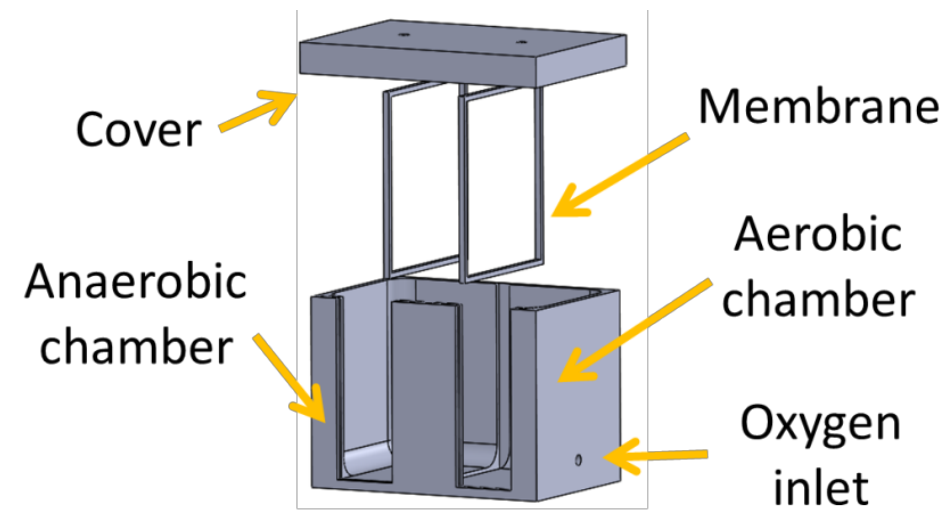

Fig. 4. Design of MFC with exchangeable membrane Source: Author's

The model was printed with $3 \mathrm{D}$ printer Zortrax $\mathrm{M} 200^{\circledR}$. Due to its unique characteristic (i.e. easy to mould, light and strong) High Impact Polystyrene (HIPS) dissolve-able filament was chosen as a coating material for MFC fabrication. HIPS is a low cost, tough plastic that is easy to thermoform and fabricate, often used for countertop point of purchase displays and indoor signs where ease of fabrication is essential. It is a thermoplastic suitable for making high quality, lightweight parts. It is soluble in D-Limonene which makes it the ideal support material. The 3D printed MFC was prepared in organic solvent before the experiment. The method of attachment membrane is shown in Fig. 5. Membrane is inserted between two frames and this module is put in special, thick channel. Good fit ensure tightness system.

\section{Experimental methodology and first test results}

Anaerobic chamber contained steel wool as an anode and sewage sludge $(500 \mathrm{~mL})$ from wastewater treatment plant was used as source of microorganisms. Aerobic compartment was filled with tap water $(500 \mathrm{~mL})$. To obtain aerobic condition the air pump was used. The chambers are physically separated with self-made agar membrane. The microorganisms were fed with $10 \%$ solution of acetic acid $(2 \mathrm{~mL})$.

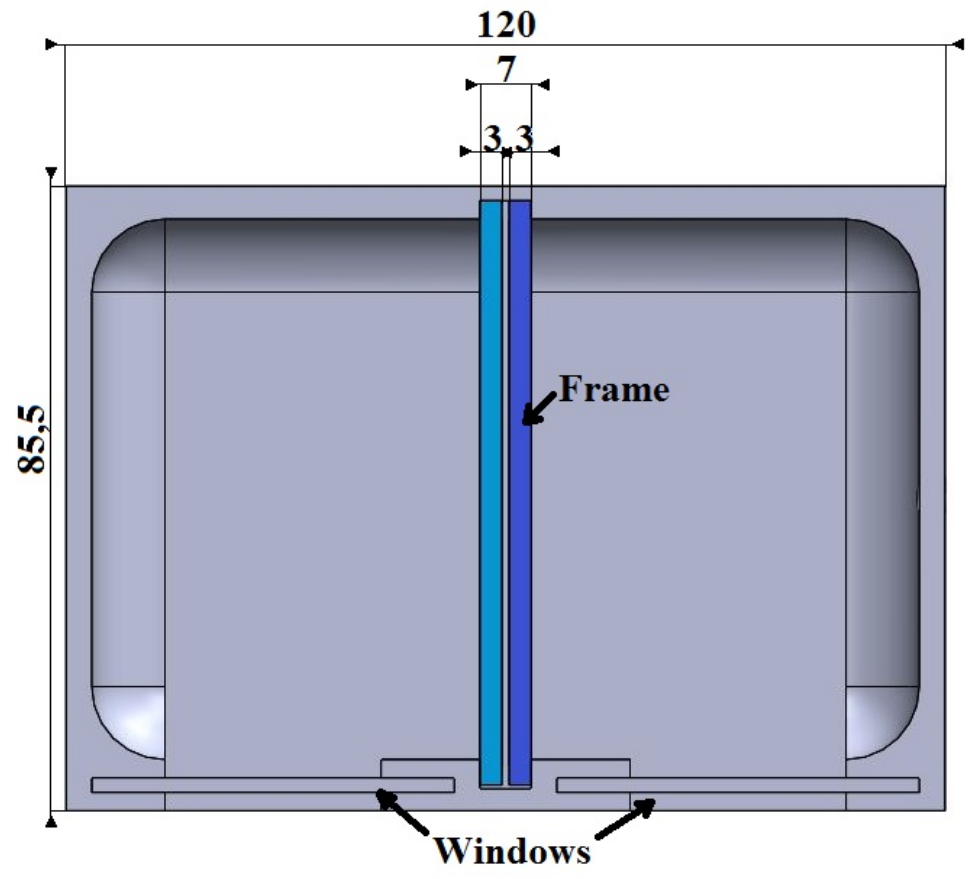

Fig. 5. MFC's view from above

Source: Author's 
Experimental system consisted of: 1 - multimeter (VOM), 2 - 3D printed MFC, 3 - air pump is shown in Fig. 6. Voltage generated by microorganisms was measured and saved the same intervals of time.

As it can be seen from the Fig. 7 the performance of MFC system was quite stable during the experiment. The highest voltage was observed at the beginning of the test $\left(20^{\text {th }}\right.$ measurement). No leakage from the device was noticed and the structure of the HIPS casing seemed to be unaffected by the introduced media. Such positive results may let to the conclusion that AM technique could successfully be applied for easy and quick fabrication of MFC for the lab-scale experiments. The next step of the study should be focused on improving the performance of MFC by its structural modifications (e.g. changing the internal porosity).

In AM technique a degree of surface modification depends on the resolution of the printer (dozens of micrometers) and the thickness of the print layer (as standard 0.4 micrometers), what allows for obtaining rough and porous structures. This can promote the formation of biofilm and the high retention of biomass in the bioreactor will be achieved. Also, the development of biofilm can eliminate the biomass wash out. Another very important issue for investigation will be to find the best thermoplastic materials for such application, which should be resistant to the aggressive media, safe for the microorganisms and durable for long-term operation.

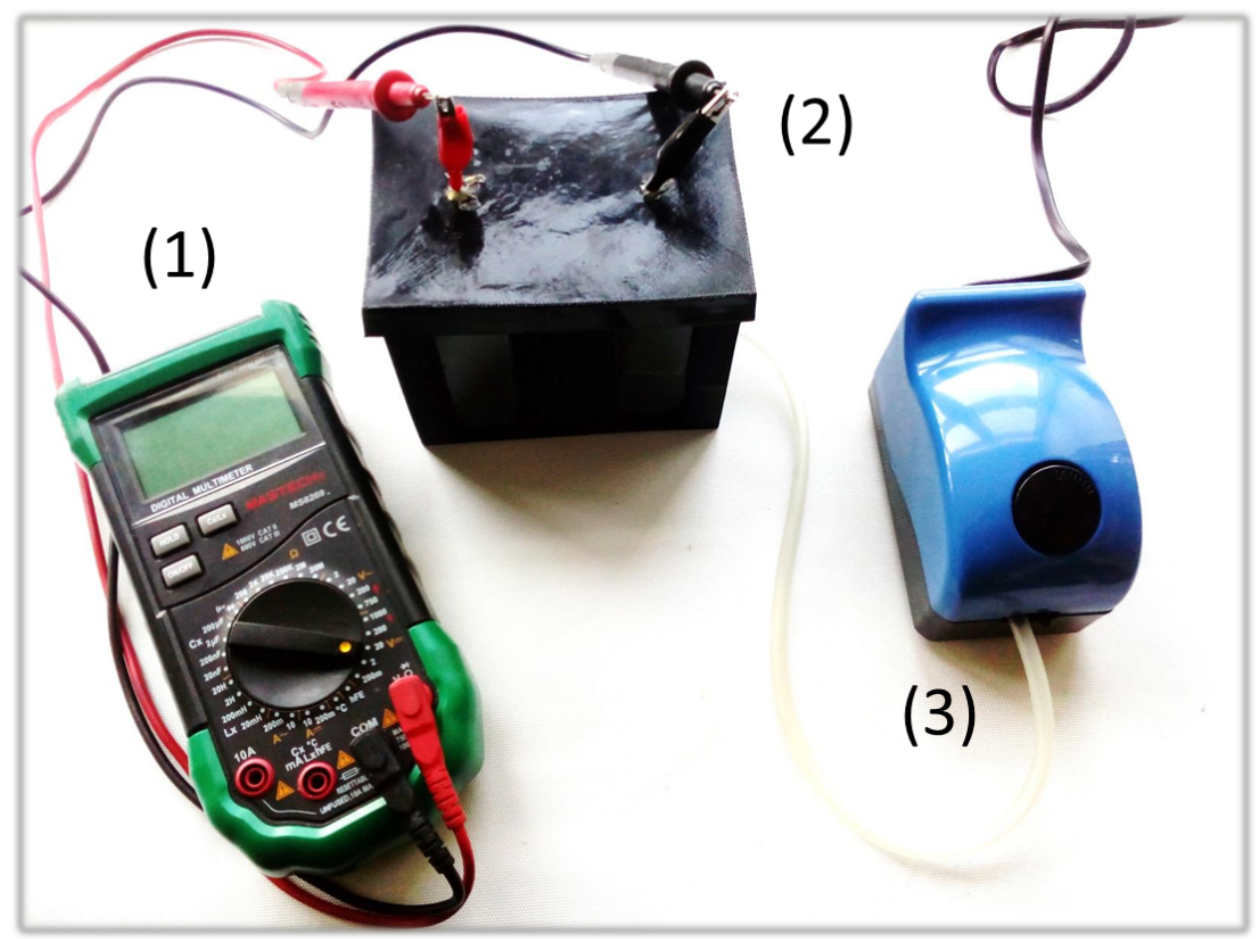

Fig. 6. Exemplary experimental system: (1) Multimeter, (2) 3D printed MFC, (3) Air pump Source: Author's 


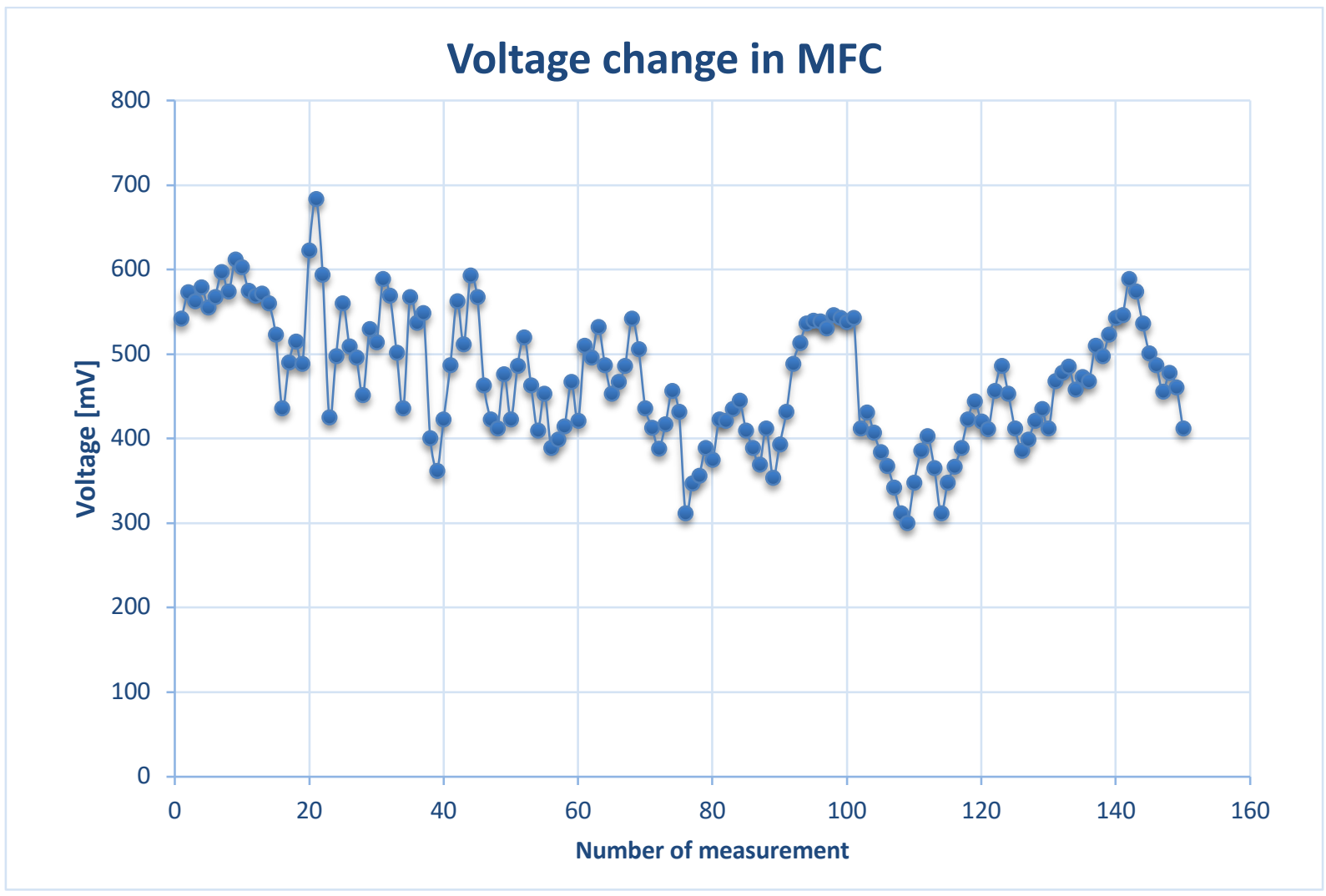

Fig. 7. Changing voltage in time Source: Author's

\section{Summary}

There are still many challenges in bioelectricity generation. Because of the promise of sustainable energy generation from different substrates such as organic wastes, research has been intensified in this field in the last few years. The power from MFC is unstable and depends on $\mathrm{pH}$, temperature, types of microbes, composition of feedstock, toxic substances and type of construction. MFC could be also used as biosensors and to produce secondary fuels (like hydrogen). The high potential hidden in waste could be used as a limitless source of energy. The proposed MFC 3D printed system with exchangeable membrane allows increasing the opportunities to research about different types, material and size of membranes. The size of 3D model could be changed and adjust to every lab test with MFC. Fast and low cost 3D printed technology provides flexibility in shape and size of device. To maximize effective specific surface area of anode, steel wool was used as a support for growing biofilm. The module where the membranes are placed enable to research the same conditions in MFC with different membrane, what reduce variable parameters. Properly selected dissolve-able filament causes stable and easy to operated working conditions. There are still many technical and economic challenges in MFC construction but if microbial fuel cells deliver on their promise wastewater will be waste not longer. In the next three years $\mathrm{CBI}$ Pro-Akademia, will have the great opportunity to support this kind of research activities. Within the International M-Era.net Project "BioElectroCathode", 3D printing technology (Additive Manufacturing) will be optimized and intensively developed to fabricate BES for industrial CO2 sequestration. Polish Partners (CBI and Omni3D Sp. z o.o.) together with their scientific partners from Cyprus will design and test in both lab- and semi-industrial scale, novel, memberaneless 3D printed bioreactors to determine their capability for real scale implementation.

\section{References}

[1] Kim, Kyoung-Yeol, et al. "Performance of anaerobic fluidized membrane bioreactors using effluents of microbial fuel cells treating domestic wastewater." Bioresource technology 208 (2016): 58-63.

[2] Logan, B. E. (2008). Microbial fuel cells. John Wiley \& Sons, 4-11. 
[3] Sikora, A., \& Sikora, R. (2005). Mikrobiologiczne ogniwa paliwowe. Biotechnologia monografie, 2(2), 68-77.

[4] Rabaey, K.; Boon, N.; Hofte, M.; Verstraete, W. (2005). Microbial phenazine production enhances electron transfer in biofuel cells. Environ. Sci. Technol., 39, 3401-3408.

[5] Shukla A.K., P. Suresh, S. Berchmans, A. Rajendran, (2004). Biological fuel cells and their applications, Current Science India, 87, 455-468

[6] Cusick R.D., Kim Y., Logan B.E.: Energy capture from thermolytic solutions in microbial reverseelectrodialysis cells. Science, 335, 1474-1477 (2012)

[7] Logan B.E., Regan J.M.: Electricity-producing bacterial communities in microbial fuel cells. Trends Microbiol. $14,512-518$ (2006)

[8]. Wang X., Feng Y.J., Lee H.: Electricity production from beer brewery wastewater using single chamber microbial fuel cell. Water Sci. Technol. 57, 1117-1121 (2008)

[9] Kim H.J., Hyun M.S., Chang I.S., Kim B.H.: A microbial fuel cell type lactate biosensor using a metal-reducing bacterium, Shewanella putrefaciens. J. Microbiol. Biotechnol. 9, 365-367 (1999)

[10] Min B., Logan B.E: Continuous electricity generation from domestic wastewater and organic substrates in a flat plate microbial fuel cell. Environ. Sci. Technol. 38, 5809-5814 (2004)

[11] Wang X., Feng Y.J., Lee H.: Electricity production from beer brewery wastewater using single chamber microbial fuel cell. Water Sci. Technol. 57, 1117-1121 (2008)

[12] Liu H., Logan B.E.: Electricity generation using an air-cathode single chamber microbial fuel cell in the presence and absence of a proton exchange membrane. Environ. Sci. Technol. 38, 4040-4046 (2004)

[13] Liu H., Ramnarayanan R., Logan B.E.: Production of electricity during wastewater treatment using a single chamber microbial fuel Cell. Environ. Sci. Technol. 38, 2281-2285 (2004)

[14] Min B., Logan B.E: Continuous electricity generation from domestic wastewater and organic substrates in a flat plate microbial fuel cell. Environ. Sci. Technol. 38, 5809-5814 (2004)

[15] Rabaey K., Clauwaert P., Aelterman P., Verstraete W.: Tubular microbial fuel cells for efficient electricity generation. Environ. Sci. Technol. 39, 8077-8082 (2005)

[16] Aelterman P., Rabaey K., Pham H.T., Boon N., Verstraete W.: Continuous electricity generation at high voltages and currents using stacked microbial fuel cells. Environ. Sci. Technol. 40, 3388-3394 (2006)

[17] Lovley D.R.: Microbial fuel cells: novel microbial physiologies and engineering approaches. Curr. Opin. Biotechnol. 17, 327-332 (2006)

[18] Reimers C.E., Girguis P., Stecher H.A., Tender L.M., Ryckelynck (N., Whaling P.: Microbial fuel cell energy from an ocean cold seep. Geobiology, 4, 123-136 (2006)

[19] Bedka, A., Brocki, K., Michalska, K. (2016). Microbial fuel cells - minireview of technology and application. Acta Innovations 19, 16-24.

[20] Kang, Y. L., Pichiah, S., \& Ibrahim, S. (2017). Facile reconstruction of microbial fuel cell (MFC) anode with enhanced exoelectrogens selection for intensified electricity generation. International Journal of Hydrogen Energy, 42(3), 1661-1671

[21] Lee J., Phung N.T., Chang I.S., Kim B.H., Sung H.C.: Use of acetate for enrichment of electrochemically active microorganisms and their 16S rDNA analyses. FEMS Microbiol. Lett. 223, 185-191 (2003) 
[22] Rosenbaum M., Zhao F., Schröder U., Scholz F.: Interfacing electrocatalysis and biocatalysis with tungsten carbide: a high-performance, noble-metal-free microbial fuel cell. Angew. Chem. Int. Ed. 45, 6658-6661 (2006)

[23] Patil S.A., Surakasi V.P., Koul S., ljmulwar S., Vivek A., Shouche Y.S., Kapadnis B.P.: Electricity generation using chocolate industry wastewater and its treatment in activated sludge based microbial fuel cell and analysis of develo ped microbial community in the anode chamber. Bioresour. Technol. 100, 5132-5139 (2009)

[24] Pham T.H., Rabaey K., Aelterman P., Clauwaert P., De Schamphelaire L., Boon N., Verstraete W.: Microbial fuel cells in relation to conventional anaerobic digestion technology. Eng. Life Sci. 6, 285-292 (2006)

[25] Sun J., Li Y., Hu Y., Hou B., Xu Q., Zhang Y., Li S.: Enlargement of anode for enhanced simultaneous azo dye decolorization and power output in air-cathode microbial fuel cell. Biotechnol. Lett. (2012), DOI 0.1007/s10529012-1002-8

[26] Chiao M., Lam K.B., Lin L.: Micromachined microbial and photosynthetic fuel cells. J. Micromech. Microeng. 16, 2547-2553 (2006)

[27] Mitra P., Hill G.A.: Continuous microbial fuel cell using a photoautotrophic cathode and a fermentative node. Can. J. Chem. Eng. 90, 1006-1010 (2012)

[28] Prasad D., Arun S., Murugesan M., Padmanaban S., Satyanarayanan R.S., Berchmans S., Yegnaraman V.: Direct electron transfer with yeast cells and construction of a mediatorless microbial fuel cells. Biosens. Bioelectron. 22, 2604-2610 (2007)

[29] Schaetzle O., Barrière F., Baronian K.: Bacteria and yeasts as catalysts in microbial fuel cells: electron transfer from microorganisms to electrodes for green electricity. Energy Environ. Sci. 1, 607-620 (2008)

[30] Sun Y., Wei J., Liang P., Huang X.: Electricity generation and microbial community changes in microbial fuel cells packed with di?erent anodic materials. Bioresour. Technol. 102, 10886-10891 (2011)

[31] Rodrigo M.A., Cañizares P., García H., Linares J.J., Lobato J. (2009). Study of the acclimation stage and of the effect of the biodegradability on the performance of a microbial fuel cell. Bioresour. Technol. 100, 47044710

[32] Leong, J. X., Daud, W. R. W., Ghasemi, M., Liew, K. B., \& Ismail, M. (2013). Ion exchange membranes as separators in microbial fuel cells for bioenergy conversion: a comprehensive review. Renew. Sust. Energ. Rev., $28,575-587$

[33] Schalenbach, M.; Hoefner, T.; Paciok, P.; Carmo, M.; Lueke, Wiebke; Stolten, Detlef (2015). Gas Permeation through Nafion. Part 1: Measurements. The Journal of Physical Chemistry C. 119: 25145-25155.

[34] Mauritz, K. A., Moore, R. B.; Moore (2004). State of Understanding of Nafion. Chemical Reviews. 104 (10): 4535-4585.

[35] Gong, Y., Radachowsky, S. E., Wolf, M., Nielsen, M. E., Girguis, P. R., \& Reimers, C. E. (2011). Benthic microbial fuel cell as direct power source for an acoustic modem and seawater oxygen/temperature sensor system. Environmental science \& technology, 45(11), 5047-5053.

[36] Pasternak, G., Greenman, J., \& leropoulos, I. (2016). Comprehensive Study on Ceramic Membranes for Low-Cost Microbial Fuel Cells. ChemSusChem, 9(1), 88-96

[37] Tront, J. M., Fortner, J. D., Plötze, M., Hughes, J. B., \& Puzrin, A. M. (2008). Microbial fuel cell biosensor for in situ assessment of microbial activity. Biosensors and Bioelectronics, 24(4), 586-590.

[38] Kim, BH.; Chang, IS.; Gil, GC.; Park, HS.; Kim, HJ. (2003). Novel BOD (biological oxygen demand) sensor using mediator-less microbial fuel cell. Biotechnology Letters. 25 (7): 541-545

[39] Chang, I. S.; Moon, H.; Jang, J. K.; Kim, B. H. (2005). Improvement of a microbial fuel cell performance as a 
BOD sensor using respiratory inhibitors. Biosensors and Bioelectronics. 20 (9): 1856-1859

[40] Heidrick, E S; Dolfing J.; Scott K.; Edwards S. R.; Jones C.; Curtis T. P. (2013). Production of hydrogen from domestic wastewater in a pilot-scale microbial electrolysis cell. Applied Microbiology and Biotechnology. 97 (15): 6979-6989.

[41] Khan, M.B.H., Kana, E.B.G., (2016). Design, implementation and assessment of a novel bioreactor for fermentative biohydrogen process development. International Journal of Hydrogen Energy 41(24), 1013610144.

[42] Papaharalabos, G., Greenman, J., Melhuish, C., leropoulos, I. (2015). A novel small scale Microbial Fuel Cell design for increased electricity generation and waste water treatment. International Journal of Hydrogen Energy 40, 4263-4268.

[43] You, J., Preen, R.J., Bull, L., Greenman, J., leropoulos, I. (2017). 3D printed components of microbial fuel cells: Towards monolithic microbial fuel cell fabrication using additive layer manufacturing. Sustainable Energy Technologies and Assessments 19, 94-101.

[44] Calignano, F., Tommasi, T., Manfredi, D., Chiolerio, A. (2015). Additive Manufacturing of a Microbial Fuel Cell-A detailed study. Scientific Reports 5, 17373.

[45] Sonawane, Jayesh M., et al. (2018) Low-cost stainless-steel wool anodes modified with polyaniline and polypyrrole for high-performance microbial fuel cells. Journal of Power Sources 379: 103-114.

[46] leropoulos, loannis, et al. (2017) "Gelatin as a promising printable feedstock for microbial fuel cells (MFC)." International Journal of Hydrogen Energy 42.3: 1783-1790. 